\title{
6
}

\section{PRESENÇA DO HINDUÍSMO NA POESIA DE CECÍLIA MEIRELES ANTES DE POEMAS ESCRITOS NA ÍNDIA ${ }^{1}$}

\section{PRESENCE OF HINDUISM IN THE POETRY OF CECÍLIA MEIRELES BEFORE POEMS WRITTEN IN INDIA}

\author{
Anderson Azevedo Ferigate ${ }^{2}$ \\ Secretaria de Educação do Estado de Minas Gerais \\ Teresinha V. Zimbrão Silva ${ }^{3}$ \\ Universidade Federal de Juiz de Fora
}

Resumo: No contexto da literatura brasileira e fora dela, a obra poética da escritora Cecília Meireles (1901-1964) é bastante conhecida. No entanto, ainda há um aspecto dessa obra pouco estudado pela crítica literária, no que diz respeito ao diálogo ceciliano com as religiões, a saber, a intensa relação que a poeta estabeleceu com o Hinduísmo. O presente artigo pretende refletir sobre essa relação, analisando alguns poemas escritos antes de ela viajar para a Índia em 1953. Esperamos mostrar que estudar a presença do Hinduísmo nos poemas anteriores a essa viagem, é, de fato, importante para compreender a obra da escritora como um todo.

Palavras-Chave: Cecília Meireles; Poesia; Hinduísmo.

1 Agradecemos a contribuição do Prof. Dr. Dilip Loundo, do Departamento de Ciência da Religião da UFJF, com quem conversamos a respeito do diálogo ceciliano com a Índia e também sobre os postulados hindus, Satyagraha e Ahimsa. O Prof. Loundo é um dos poucos pesquisadores que também escreveu a respeito do tema desse artigo (LOUNDO, Dilip. Cecília Meireles e a Índia: viagem e meditação poética. In: GOUVEA, Leila. V. B. Ensaios sobre Cecília Meireles. São Paulo: Humanitas, 2007, p. 129-136). Ele também traduziu, no contexto indiano, diversos poemas de Cecília Meireles para o inglês (MEIRELES, Cecília. Travelling and Meditating: Poems writen in India and others poems. Trad. Rita R, Sanyal e Dilip Loundo. Nova Delhi: Embaixada do Brasil, 2003, edição bilíngue que utilizamos aqui).

2 Endereço eletrônico: andersonferigate@hotmail.com.

3 Endereço eletrônico: teresinha.zimbrao@gmail.com. 
Abstract: In the context of Brazilian literature and outside it, the poetic work of the writer Cecilia Meireles (1901-1964) is well known. However, there is still an aspect of this work little studied by literary criticism, with regard to the Cecilian dialogue with religions, namely, the intense relationship that the poet established with Hinduism. The present article intends to reflect on this relationship, analyzing some poems written before she traveled to India in 1953. We hope to show that studying the presence of Hinduism in the poems prior to that trip, is, in fact, important to understand her work as a whole.

Keywords: Cecília Meireles; Poetry; Hinduism.

\section{INTRODUÇÃO}

Desde muito jovem, quando ainda era ligada às revistas simbolistas Árvore Nova, Terra de Sol e Festa (entre 1919 e 1927), e acompanhada de outros escritores cristãos como Tasso da Silveira e Andrade Murici, Cecília Meireles buscava uma nova forma de fazer literatura. O grupo espiritualista de Cecília evoluiu à margem do Modernismo, priorizando pensamento filosófico-religioso, tradição e universalidade. Porém, Cecília, diferente de seus companheiros de revista, não trabalhava apenas com o pensamento filosófico cristão. A sua universalidade também vinha do pensamento filosófico das tradições religiosas da Índia, as quais ela conhecia desde muito jovem e que seriam presenças determinantes ao longo da sua obra. A presença do Hinduísmo em Cecília constitui, portanto, o resultado das relações intensas que a escritora estabeleceu com a cultura e religiões indianas, presença que se registra desde antes dela viajar para a Índia em 1953, e publicar depois, em 1961, Poemas escritos na Índia. Dentre os valores hindus presentes em Cecília, sobressai o que a própria poeta chamaria de uma certa ausência do mundo. Essa visão de ausência, de sobrevoo, só é possível quando o eu-lírico renuncia a si mesmo e se distancia de tudo quanto foi vivido, amado ou sofrido. Em outras palavras, um sobrevoo que aponta para o desapego. Note-se que na tradição hindu o desapego, não só de bens materiais, mas também, e ainda mais importante, o desapego de si, deixando para trás vaidade 
e orgulho, exige o compromisso com a Verdade, Satyagraha, e a Não-violência,

Ahimsa, princípios sagrados do Hinduísmo que o grande líder hindu Mahtama

Gandhi (1869-1948) incorporou na sua filosofia, e que encontrariam em Cecília uma ouvinte atenta ${ }^{4}$ Pois registrar os rastros dessa presença do Hinduísmo na poesia de Cecília Meireles, antes de Poemas escritos na Índia, é a proposta desse trabalho 5 .

\section{A PRODUÇÃO INICIAL}

Espectros, de 1919 faz parte da produção inicial ceciliana que a própria autora preferiu retirar da Obra Poética de 1958, porque nos poemas desse livro de estreia era possível perceber uma forte carga simbolista. Em Espectros a tradição hindu não aparece apenas de maneira sutil, ela é explícita, por exemplo, no poema "Brâmane":

Plena mata. Silencio. Nem um pio

De ave ou bulir de folha. Unicamente

Ao longe, em suspiroso murmúrio,

Do Ganges rola a fúlgida serpente.

Sem ter no pétreo corpo um arrepio,

$\mathrm{Nu}$, braços no ar, de joelhos, fartamente,

Esparsa a barba ao peito, na silente

4 Os princípios sagrados do Hinduísmo Satyagraha e Ahimsa, tal como defendidos por Gandhi, comparecem definidos na sua autobiografia: GANDHI, Mahatma. Autobiografia: minha vida e minhas experiências com a Verdade. Trad. Humberto Mariotti e outros. São Paulo: Palas Athena, 2001.

5 É importante sublinhar, no que diz respeito ao diálogo ceciliano com o Oriente, que além dos trabalhos de Dilip Loundo, que se concentram particularmente no diálogo com a Índia, a fortuna crítica de Cecília Meireles conta também com os seguintes trabalhos: MELLO, Ana Maria Lisboa; UTÉZA, Francis. Oriente e Ocidente na poesia de Cecília Meireles. Porto Alegre: Libretos, 2006; MARCHIORO, Camila. Cecília Meireles e os símbolos do Absoluto, 2014, $124 \mathrm{f}$. Dissertação. (Mestrado no Programa de Pós-Graduação em Letras) Departamento de ciências Humanas, Universidade Federal do Paraná, Curitiba; MARCHIORO, Camila. Poesia do indizível: Camilo Pessanha e Cecília Meireles em comparação, 2018, 243 p. Tese. (Doutorado no Programa de PósGraduação em Letras) Departamento de ciências Humanas, Universidade Federal do Paraná, Curitiba. 
Mata, o Brâmane sonha. Pelo estio,

Ao sol, que os céus abrasa e o chão calcina, Impassível, a sílaba divina

Murmura... E a cólera hibernal do vento

Não ousa à barba estremecer um fio

Do esquelético hindu, rígido e frio,

Que contempla, extasiado, o firmamento. (MEIRELES, 2003, p. 210)

O poema revela a figura mítica do sábio hindu idealizado pelo eu-lírico ceciliano. Alguém apartado e desapegado do mundo que contempla os céus em absoluta concentração, provavelmente trabalhando a Não-Violência e buscando a Verdade. Vemos, presente no texto, o valor da contemplação na busca por uma comunhão com o todo. Se a contemplação é feita, tanto pelo sábio hindu, quanto pela poeta, como exercício do amor pelas coisas contempladas, esse exercício deve ser feito com muita disciplina e desapego, ou seja, o provável arrebatamento proporcionado pelos sentidos, expostos à contemplação, não pode turvar a mente, cegando para a realidade.

Notemos, portanto, a importância da noção de sobrevoo. O eu-lírico descreve muito bem o sábio hindu como se o visse de cima e fosse se aproximando para observar não só a sua aparência física, mas também a sua postura, o seu gestual. Ao mesmo tempo em que proporciona ao leitor esse arrebatamento da contemplação, que vem especialmente ao final do poema com a visão do firmamento, não perde ele de vista o dado real proporcionado seja pelo ambiente, a mata, o Ganges, o vento, o sol, seja pelo próprio posicionamento do corpo do sábio: o pétreo corpo nu, braços no ar, de joelhos, a esparsa barba ao peito.

Segundo Dilip Loundo, essa produção inicial, da qual o poema acima é um exemplo perfeito, é caracterizada pelos estudos que Cecília Meireles fez do lirismo místico do poeta indiano, e Nobel de Literatura em 1913, Rabindranath Tagore (1861-1941). A presença oriental acontece nas palavras do pesquisador, 
"de um modo muito limitado e preparatório". (2007, p. 132). Ela vem dos estudos orientalistas predominantes na época, e que estavam contaminados por preconceitos e estereótipos vindos do idealismo alemão, em especial do pessimismo de Arthur Schopenhauer (1788 - 1860), o primeiro europeu a usar em sua filosofia elementos do Hinduísmo e do Budismo a partir de leituras que fez dos Upanisads ${ }^{6}$. A leitura equivocada se dá, em grande medida, porque o filósofo europeu nunca teve contato direto com as obras originais, ficando restrito às primeiras traduções do texto hindu para o latim. Essa visão de uma mística oriental estereotipada pode ter levado Meireles a escrever "O diviníssimo poeta", de 1924. A idealização do grande poeta indiano faz o eu-lírico temer sua visita ao Brasil, onde as pessoas não o compreenderiam:

Rabindranath! Rabindranath! Rabindranath!

Por que deixas a luz mística do teu Oriente,

Que é o corpo de ouro dos ídolos de lá

Onde os ídolos são a luz do sol de toda a gente!

Há tão profundo, tão vasto e tão lânguido encanto

Nos teus poemas sagrados, pairando como luas

Sobre o mundo, que eu nunca soube, do teu canto,

Se as palavras eram de Deus ou se eram tuas...

E tu estavas perdido no prestígio glorioso da ausência...

Penso que vais aparecer... Meus olhos andam tristes...

Os tempos não têm clemência! Os homens não têm clemência!

E todos vão saber que vives, que és, que existes!...

Sofro porque eras o Todo Longe, o Todo Altura, O Creador, que ninguém sabe como será...

É muito, é enormemente doloroso ser criatura...

Rabindranath! Rabindranath! Rabindranath! (MEIRELES, 2003, p. 212)

6 Os Upaniṣads correspondem à última seção dos Vedas, os textos sagrados do Hinduísmo, escritos em sânscrito, que tratam de questões metafísicas e de salvação. Nesse artigo consultamos a seguinte tradução: Upanisads. Trad. Patrick Olivelle. New York: Oxford University Press, 2008. 
O eu-lírico reconhece a imensa idealização que ele mesmo faz do escritor indiano, "Todo longe”, "Todo Altura”. Em sua interpretação, a presença física de Tagore o tiraria do pedestal sagrado que o eu-lírico havia criado para ele. Era como se a Verdade se materializasse e essa possibilidade gerasse uma angústia tremenda, talvez, pela possibilidade de Tagore não ser aquilo pelo qual tanto ansiara o eu-lírico. Notemos a separação no poema entre o que é divino - o campo dos ídolos que guiam as pessoas como a luz do sol - e o que é humano - o campo daqueles quenão têm clemência. Entre ser criador e criatura, Tagore, na interpretação do eu-lírico, deveria escolher a divindade.

O que se observa dos rastros do Hinduísmo nessa produção inicial de Cecília Meireles é algo ainda muito sutil. De maneira um pouco velada, temos o compromisso dessa poesia com a mística indiana, onde sobressai uma escrita com traços simbolistas, buscando sentimentos universais, expressos na forma como o eu-lírico contempla o mundo e o descreve através de um compromisso com a Verdade. Essa proposta ganhará mais robustez ao longo dos anos, porém, desde o início, percebe-se a intenção da poeta em ser fiel a esse compromisso.

\section{CÂNTICOS, VIAGEM E MAR ABSOLUTO}

Cânticos é uma obra publicada postumamente, em 1981, mas, segundo Dilip Loundo (2007, p. 135) a datação estimada de sua redação é 1927, portanto, em um período de transição entre a produção inicial e o livro Viagem que seria publicado em 1939. É um poema dividido em 26 cânticos no qual Meireles evidencia toda a sua trajetória espiritual e sua intuição. Possui um aspecto exortativo em que a poeta se reveste da aura de guru e o leitor passa a ser o seu aprendiz. Loundo aponta que a própria estrutura do livro se assemelha em muito à da literatura prakaraṇ, que são tratados introdutórios, em sua maioria 
versificados, da tradição Vedānta7. Para o pesquisador é possível analisar esse livro como se fosse uma trilogia que mostra o caminhar da poeta rumo a um conhecimento não dualista, presente nos Upaniṣads: o desapego do mundo; o desapego de si mesmo; a compreensão de unidade total entre si mesmo e o mundo. O "Cântico I", que abre o livro, é um bom exemplo do desapego ao mundo:

Não queiras ter Pátria.

Não dividas a Terra.

Não dividas o Céu.

Não arranques pedaços ao mar.

Não queiras ter.

Nasce bem alto,

Que as coisas todas serão tuas.

Que alcançarás todos os horizontes.

Que o teu olhar, estando em toda parte

Te ponha em tudo,

Como Deus. (MEIRELES, 1981, p. 4)

No poema, o guru/poeta aconselha, basicamente, que o seu aprendiz/leitor abandone todas as preocupações com o mundo, que não se preocupe com Pátria, Terra ou Céu; o importante é não querer ter alguma coisa. Quando se chega a esse nível, as coisas às quais renunciou já serão suas porque estará mirando o horizonte infinito que o colocará em comunhão com Deus. E Deus é a Verdade. Portanto, esse desapegar do mundo faz parte do Satyagraha. O guru incentiva o aprendiz a livrar-se de todo o peso do mundo, alimentar-se apenas do necessário, vestir-se apenas com seu vestuário simples, possuir apenas um lugar modesto para morar, porque nenhuma dessas coisas constitui um ganho Verdadeiro. Só

7 A filosofia Vedañta é uma tradição espiritual explicada nos Upanișads que se preocupa, principalmente, com a autorrealização, através da qual se pode compreender qual a real natureza da realidade. O Vedañta - que significa "a meta de todo o conhecimento" - por definição não se restringe ou está confinado a um único livro, e não é a única fonte da filosofia vedântica. Baseiase nas leis espirituais imutáveis que são comuns às tradições religiosas e espirituais indianas. Nesse artigo, além dos Upanisads, consultamos ainda sobre o Hinduísmo: FLOOD, Gavin. Uma introdução ao Hinduísmo. Trad. Dilip Loundo; Fernanda Winter. Juiz de Fora: Ed. UFJF, 2014. 
se vê bem no horizonte estando despido das coisas do mundo para entrar em comunhão com o todo e encontrar a divindade. Exemplo maior desse desapego mundano é o "Cântico XIV":

Eles te virão oferecer o ouro da Terra.

E tu dirás que não.

A beleza.

E tu dirás que não.

O amor.

E tu dirás que não, para sempre.

Eles te oferecerão o ouro d'além da Terra.

E tu dirás sempre o mesmo.

Porque tens o segredo de tudo.

E sabes que o único bem é o teu. (MEIRELES, 1981, p. 30)

Aqui, fica clara a necessidade de não se deixar corromper na busca pelos supostos tesouros do mundo. O ouro, a beleza e o próprio amor carnal podem desviar o leitor/aprendiz de seu caminho, o caminho da Verdade. Mesmo que se ofereçam coisas surpreendentes ou inimagináveis, nenhuma delas pode tirar o Verdadeiro valor que está dentro de si, no mais íntimo do ser humano. Não há poder sobre a Terra ou fora dela capaz de abalar esse segredo inviolável que todo ser carrega.

Já o desapego de si pode ser conferido, por exemplo, no "Cântico IV":

Adormece teu corpo com a música da vida.

Encanta-te.

Esquece-te.

Tem por volúpia a dispersão.

Não queiras ser tu.

Queira ser a alma infinita de tudo.

Troca o teu curto sonho humano

Pelo sonho imortal.

O único.

Vence a miséria de ter medo.

Troca-te pelo Desconhecido.

Não vês, então, que ele é maior?

Não vês que ele não tem fim?

Não vês que ele é tu mesmo? 
Os conselhos desse cântico parecem girar em torno de um estranho paradoxo: no terceiro verso o eu-lírico aconselha "Esquece-te" e, ao fim, indaga como se fosse um lamento, "Tu que andas esquecido de ti?." No entanto, temos que compreender o caminho existencial e filosófico que o aprendiz deve trilhar para chegar a um nível de autoconhecimento que o possibilite perceber que, somente desapegando-se de si mesmo, ele terá a compreensão da sua participação no todo. É necessário se encantar com o mundo, deixar-se levar pelos mistérios da vida, superar os próprios medos, esquecer-se e se sentir integrado à "música da vida". Só assim o aprendiz poderá vislumbrar o Desconhecido, que não é outro senão ele mesmo, que havia se perdido. É um círculo que pode ser interpretado como se, através do despojamento de si mesmo, ele descobrisse que o grande mistério do mundo sempre esteve no mais íntimo de seu ser.

Desapegar-se de si mesmo, renunciar, são elementos que indicam a parte final da trilogia proposta por Loundo para se entender o livro e pode ser verificada, por exemplo, no "Cântico XI":

Renova-te.

Renasce em ti mesmo.

Multiplica os teus olhos, para verem mais.

Multiplica os teus braços para semeares tudo.

Destrói os olhos que tiverem visto.

Cria outros, para as visões novas.

Destrói os braços que tiverem semeado,

Para se esquecerem de colher.

Ser sempre o mesmo.

Sempre outro.

Mas sempre alto.

Sempre longe.

E dentro de tudo. (MEIRELES, 1981, p. 28) 
Novamente, um cântico que trabalha com dicotomias. Os conselhos parecem contraditórios, é preciso renovar-se, renascer em si mesmo e, para isso, a princípio, é preciso ver mais, é preciso semear mais. Então, o conselho se inverte dizendo que se deve apagar o que os olhos viram para que surjam novas visões, que se deve destruir os braços que antes haviam semeado as coisas novas para que se esqueça da própria colheita. Só assim se vai longe, se percebe o mundo e se consegue perceber a si mesmo, desapegado, e dentro do mundo, como uma unidade perfeita. Essa comunhão é mais clara ainda no "Cântico XXII":

Não busques para lá.

O que é, és tu.

Está em ti.

Em tudo.

A gota esteve na nuvem.

Na seiva.

No sangue.

$\mathrm{Na}$ terra.

E no rio que se abriu no mar.

E no mar que se coalhou em mundo.

Tu tiveste um destino assim.

Faze-te à imagem do mar.

Dá-te à sede das praias.

Dá-te à boca azul do céu.

Mas foge de novo à terra.

Mas não toques nas estrelas.

Volve de novo a ti.

Retoma-te. (MEIRELES, 1981, p. 44)

Temos aqui a visão não dualista do mundo. Os primeiros versos já entregam que não é uma busca espiritual para se fazer longe; tudo, na Verdade, está dentro de si, assim como o próprio ser está em tudo. Devemos nos fazer à imagem do mar, cujo interior é formado de infinitas gotas que, por sua vez, estão integradas em tudo. Entregue-se aos mistérios do mundo, à contemplação, mas não se esqueça de si, pois é preciso retornar de onde tudo começou, porque essa é a força de um mundo não-dualista. Só assim a busca pela Verdade terá algum 
sentido. A Verdade e a eternidade que residem no próprio ser ou nos versos finais do "Cântico II": "É a tua eternidade/ é a eternidade/ És tu”.

O amadurecimento literário de Meireles e uma presença do Hinduísmo mais nítida em sua obra ficam mais perceptíveis a partir da coletânea Viagem, de 1939. A obra registra doze poemas que podem ser lidos como doze etapas de uma trajetória espiritual em que se fundem poesia e vida, poeta e natureza, o mundano das criaturas e o divino acessado pelo caminho da Verdade. O livro, premiado um ano antes de sua publicação pela Academia Brasileira de Letras, marca a aproximação da poeta com o movimento modernista brasileiro. Segundo Dilip Loundo,

O movimento da poeta no sentido de expandir suas opções estéticas para além do parnasianismo e do simbolismo dá-se, concomitantemente, com a percepção gradual de que uma ascese espiritual só se realiza em sua plenitude caso ela busque, positivamente, o conhecimento do mundo, jamais a evasão do mesmo. (LOUNDO, 2008, p. 132)

Então, é o próprio conhecimento do mundo que pode ajudar a poeta em sua busca espiritual, e durante muitos anos ela aprofundou seus estudos sobre a cultura, a filosofia e os idiomas da Índia. O contato, de fato, com os postulados gandhianos de Satyagraha e Ahimsa se dá a partir do conhecimento da luta do Mahatma pela causa dos indianos, a princípio na África do Sul e, posteriormente, na própria Índia, pela Independência do país. Gandhi passou a ser a figura política e espiritual indiana mais admirada por Cecília Meireles. Para aumentar seu conhecimento do mundo, a escritora se aprofunda nos ensinamentos tradicionais dos Upanisads que a fazem ultrapassar em muito aquilo que conhecia da Índia na época de sua produção inicial. O poema mais célebre desta coletânea, "Motivo", já traz em si elementos desse aprendizado de Meireles sobre a filosofia indiana: 
Eu canto porque o instante existe e a minha vida está completa. Não sou alegre nem sou triste: sou poeta.

Irmão das coisas fugidias, não sinto gozo nem tormento. Atravesso noites e dias no vento.

Se desmorono ou se edifico, se permaneço ou me desfaço, _ não sei, não sei. Não sei se fico ou passo.

Sei que canto. E a canção é tudo. Tem sangue eterno a asa ritmada. E um dia sei que estarei mudo: _. mais nada. (MEIRELES, 1972, p. 63)

Dilip Loundo (2007, p. 137) aponta para uma mudança de direcionamento metafísico que pode ser percebida nesse poema. Ao invés de um caminho que busca transcender o mundo, a poeta volta sua percepção para o Eu. É um poema que fala de si, de um eu-lírico que é capaz de perceber-se diante da vida, diante do tempo, que ele sabe ser fugidio, percebendo o valor do momento presente. Em termos metafísicos, esse olhar para si mesmo o faz perceber também o mundo circundante. Ambos, o eu e o mundo, revelados por um lirismo maduro, funcionam como se fossem o ponto inicial e o ponto final de sua busca filosóficoespiritual. Novamente, podemos ver, em cada estrofe desse poema, o compromisso do eu-lírico com a Verdade, que o faz reconhecer-se diante do próprio tempo como poeta que canta o próprio instante, sem saber ou sem se importar com a transitoriedade da existência. A única Verdade é que se canta e a canção é tudo.

Outra revelação feita a partir da busca da Verdade, e refletindo sobre o próprio eu, está no poema "Retrato": 
Eu não tinha esse rosto de hoje, assim calmo, assim triste, assim magro, nem estes olhos tão vazios, nem o lábio amargo.

Eu não tinha essas mãos sem força, Tão paradas e frias e mortas; eu não tinha este coração que nem se mostra.

Eu não dei por esta mudança, Tão simples, tão certa, tão fácil: _Em que espelho ficou perdida a minha face? (MEIRELES, 1972, pp. 63-64)

O rosto de hoje, calmo, triste, magro, com olhos tristes e lábio amargo, certamente revela algo que tinha passado despercebido até então, e não é apenas o fato de que o tempo passou para o corpo, mas que algo no interior da alma também se modificou e envelheceu. Temos uma dicotomia entre o estado do corpo físico - representado nas mãos paradas, frias ou mortas - e o estado emocional - representado em um coração que nem se mostra. Há nesse poema os rastros da alma, deixados no corpo, e que alertam sobre os desenganos do mundo. Somente buscando a Verdade dentro de si, e desapegando-se do ego, o eu-lírico poderá extravasar a sua dúvida existencial.

A Não-Violência gandhiana pode ser notada, ainda que de maneira vaga, no grande poema "Marcha", também parte da coletânea Viagem. O próprio título indica um poema de inspiração militar, de que algo será posto em marcha:

As ordens da madrugada romperam por sobre os montes: nosso caminho se alarga sem campos verdes nem fontes. Apenas o sol redondo e alguma esmola de vento quebram as formas do sono com a idéia do movimento. 
Vamos a passo e de longe;

entre nós dois anda o mundo, com alguns mortos pelo fundo.

As aves trazem mentiras

de países sem sofrimento.

Por mais que alargue as pupilas, mais minha dúvida aumento.

Também não pretendo nada senão ir andando à toa, como um número que se arma e em seguida se esboroa, - e cair no mesmo poço de inércia e de esquecimento, onde o fim do tempo soma pedras, águas, pensamento.

Gosto da minha palavra pelo sabor que lhe deste: mesmo quando é linda, amarga como qualquer fruto agreste. Mesmo assim amarga, é tudo que tenho, entre o sol e o vento: meu vestido, minha música, meu sonho e meu alimento.

Quando penso no teu rosto, fecho os olhos de saudade; tenho visto muita coisa, menos a felicidade. Soltam-se os meus dedos tristes, dos sonhos claros que invento. Nem aquilo que imagino já me dá contentamento.

Como tudo sempre acaba, oxalá seja bem cedo! A esperança que falava tem lábios brancos de medo.

O horizonte corta a vida isento de tudo, isento... Não há lágrima nem grito: apenas consentimento. (MEIRELES, 1972, pp. 70-72) 
É um poema sobre duas pessoas: o eu-lírico e um outro e, entre eles, um mundo em marcha. A cadência começa de maneira sutil, rompendo os montes. Apenas um pouco de sol e vento sugerem o movimento. Na segunda estrofe, presenciamos o eu-lírico duvidar da existência de países sem sofrimento. Uma mentira contada através dos tempos? Seria possível um lugar sem fome e sem guerra? Seria possível a Não-Violência exterior? Na terceira estrofe, o foco é sobre si mesmo. Nesse caso, importa destacar a expressão poética "número que se arma e em seguida se esboroa". O eu cai no mesmo lugar do outro, parado e esquecido mesmo com o mundo em marcha. Na sequência, o poema revela a estranha dependência do eu-lírico em relação ao outro, a quem devota o dom de saborear suas próprias palavras por mais amargas que sejam e de quem o próprio rosto lhe dá saudade.

Temos, então, uma inquietação que podemos transpor do externo para o interno. Se não é possível um mundo sem sofrimento, eu posso me livrar daquilo que me faz sofrer? O desejo de um mundo pacífico não seria também o desejo de pacificar a própria alma? No final, o poema deixa seus leitores sem uma resposta. A esperança tem medo, não há no futuro qualquer resposta: "Não há lágrima nem grito: apenas consentimento".

Já em outro livro, no poema "Mar Absoluto", poema principal da coletânea de mesmo título publicada em 1945, temos toda essa caminhada da poeta rumo ao autoconhecimento e à busca da Verdade absoluta exposta de maneira bem significativa. Nas primeiras quatro estrofes temos:

Foi desde sempre o mar,

E multidões passadas me empurravam

como o barco esquecido.

Agora recordo que falavam

da revolta dos ventos,

de linhos, de cordas, de ferros,

de sereias dadas à costa. 
E o rosto de meus avós estava caído

pelos mares do Oriente, com seus corais e pérolas,

e pelos mares do Norte, duros de gelo.

Então, é comigo que falam,

sou eu que devo ir.

Porque não há ninguém,

tão decidido a amar e a obedecer a seus mortos (...) (MEIRELES, 1972, p. 103)

O eu-lírico começa o poema falando de uma jornada marítima dentro de um mar absoluto, como sugere o título e, portanto, totalizante, e que pessoas que habitavam seu passado é que o empurravam dentro desse mar: vozes que falavam de instrumentos (linhos, cordas, ferros) e fantasia (sereias). Os antepassados da poeta são uma forte presença nesse mar infinito. A respeito dos "mares do oriente", é importante lembrar das histórias da Índia, contadas pela avó açoriana de Cecília Meireles. Essas vozes mortas evocadas do passado são respeitadas, são a Verdadeira mola propulsora da busca ao infinito mar. Nas últimas três estrofes é esclarecido que, além desse mar à sua frente, existe ainda um outro:

Não é apenas este mar que reboa nas minhas vidraças, mas outro, que se parece com ele como se parecem os vultos dos sonhos dormidos.

E entre água e estrela estudo a solidão.

E recordo minha herança de cordas e âncoras, e encontro tudo sobre-humano.

E este mar visível levanta para mim uma face espantosa.

E retrai-se, ao dizer-me o que preciso.

E é logo uma pequena concha fervilhante, nódoa líquida e instável, célula azul sumindo-se

8 "Minha avó, que falava uma linguagem camoniana, costumava dizer, em certas oportunidades: 'Cata, cata, que é viagem da Índia!' Eu ainda não conhecia o sentido náutico do verbo 'catar': mas parecia-me que, com aquele estribilho, tudo andava mais depressa, como para uma urgente partida" (MEIRELES, 2016, p. 36). 
no reino de um outro mar:

ah! do Mar Absoluto. (MEIRELES, 1972, p. 105)

Existe um mar-espelho refletindo o primeiro, e povoado de sonhos. $\mathrm{Na}$ solidão, o eu-lírico embalado pela memória se defronta com o mar visível que revela, através de pequenos detalhes (concha fervilhante, nódoa líquida, célula azul), o outro mar, o mar absoluto e verdadeiro, a própria Verdade por que tanto anseia o eu-lírico.

Em janeiro de 1948, sob o impacto da morte de Gandhi, Cecília Meireles escreveu o poema "Elegia sobre a morte de Gandhi", poema exemplar no que se refere à presença do Hinduísmo e dos postulados gandhianos de Satyagraha e Ahimsa na sua obra. Contudo, sua análise fica para um outro trabalho.

\section{CONSIDERAÇÕES FINAIS}

A presença do Hinduísmo na poesia de Cecília Meireles constitui o resultado das relações intensas que a poeta estabeleceu com a cultura e religiões indianas. É verdade que essa presença se acentuará muito depois da sua viagem à Índia em 1953: Meireles publicará em 1961 a coletânea Poemas escritos na Índia, e, postumamente, em 1999, Crônicas de viagem, que inclui as crônicas escritas na Índia. Contudo, esperamos ter confirmado nesse trabalho, ao analisarmos alguns poemas escritos antes de ela viajar, que notar essa presença desde os poemas anteriores à viagem, é, de fato, importante para se compreender a sua obra como um todo. Como mencionamos, pode-se notar, desde os poemas iniciais, o quanto o eu-lírico contempla o mundo e o descreve através de um compromisso com a Verdade, como também pode-se notar o quanto essa proposta vai ganhando mais robustez com o passar dos anos. A intenção da poeta em ser fiel a esse compromisso pode ser traçada da juventude à maturidade. Portanto, os rastros do Hinduísmo na poesia ceciliana se tornariam depois marcas profundas. 


\section{REFERÊNCIAS}

FLOOD, Gavin. Uma introdução ao Hinduísmo. Trad. Dilip Loundo; Fernanda Winter. Juiz de Fora: Ed. UFJF, 2014

GANDHI, Mahatma. Autobiografia: minha vida e minhas experiências com a Verdade. Trad. Humberto Mariotti e outros. São Paulo: Palas Athena, 2001.

GOUVEIA, Margarida Maia (org.). Ensaios sobre Cecília Meireles. São Paulo: Humanitas, 2008.

LOUNDO, Dilip. Cecília Meireles e a Índia: viagem e meditação poética. In: GOUVEA, Leila. V. B. (org.). Ensaios sobre Cecília Meireles. São Paulo: Humanitas, 2008, p. 129-136.

MARCHIORO, Camila. Cecília Meireles e os símbolos do Absoluto, 2014, 124 f. Dissertação. (Mestrado no Programa de Pós-Graduação em Letras) Departamento de ciências Humanas, Universidade Federal do Paraná, Curitiba.

MARCHIORO, Camila. Poesia do indizível: Camilo Pessanha e Cecília Meireles em comparação, 2018, 243 p. Tese. (Doutorado no Programa de Pós-Graduação em Letras) Departamento de ciências Humanas, Universidade Federal do Paraná, Curitiba.

MEIRELES, Cecília. Cânticos. São Paulo: Moderna, 1981.

MEIRELES, Cecília. Flor de poemas. Rio de Janeiro: José Aguilar, 1972.

MEIRELES, Cecília. O que se diz e o que se entende. São Paulo: Global, 2016.

MEIRELES, Cecília. Travelling and Meditating: Poems writen in India and others poems. Trad. Rita R. Sanyal e Dilip Loundo. Nova Delhi: Embaixada do Brasil, 2003.

MEIRELES, Cecília. Viagem. São Paulo: Global, 2012.

MEIRELES, Cecília. Mar absoluto e outros poemas. São Paulo: Global, 2015.

MELLO, Ana Maria Lisboa; UTÉZA, Francis. Oriente e Ocidente na poesia de Cecília Meireles. Porto Alegre: Libretos, 2006.

Upanisads. Trad. Patrick Olivelle. New York: Oxford University Press, 2008.

Nota do editor:

Artigo submetido para avaliação em: 15 de março de 2021.

Aprovado em sistema duplo cego em: 17 de agosto de 2021. 